\title{
Cognitive Impairment in Older Adults and Therapeutic Strategies
}

\author{
Thomas J. Montine, Syed A. Bukhari, and Lon R. White
}

Department of Pathology, Stanford University, Stanford, California (T.J.M., S.A.B.) and Pacific Health Research and Education Institute, Honolulu, Hawaii (L.R.W.)

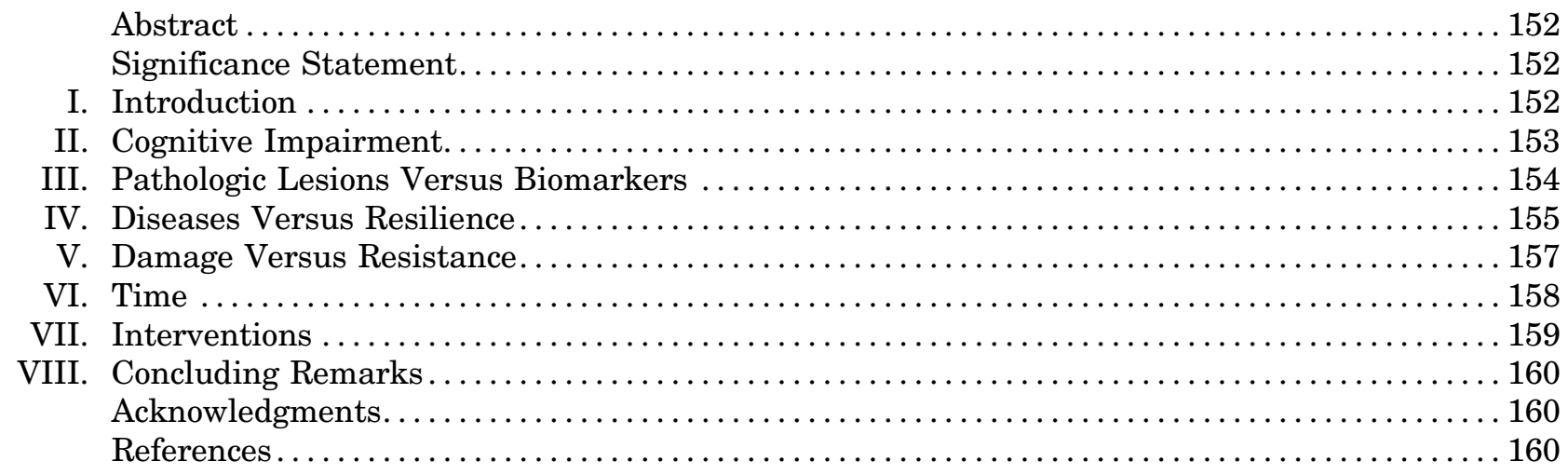

\begin{abstract}
Cognitive impairment and its severe form dementia are increasingly prevalent in older adults and loom as a public health disaster unless effective interventions are developed. Cognitive impairment is a convergent trait caused by damage from an idiosyncratic mix of four prevalent diseases (Alzheimer disease; vascular brain injury; Lewy body diseases, such as Parkinson disease and dementia with Lewy bodies; and limbic-predominant age-related transactive response DNA-binding protein 43 encephalopathy) that is counterbalanced by individually varying resilience, which is comprised of reserve and compensation. Brain regional damage from each of these four prevalent diseases is generated by the net effect of injury and (mal)adaptive response and is accompanied by characteristic lesions.
\end{abstract}

Existing therapeutics enhance resilience, whereas most agents under development target mechanisms of damage with only suppression of vascular brain injury yet to show therapeutic promise. We hope to anticipate future tailored interventions that target mechanisms of damage and thereby avert the oncoming surge of cognitive impairment and dementia in older adults.

Significance Statement-Brain regional damage is generated by the net effect of injury and (mal)adaptive response. The extent to which signs and symptoms of such damage occur is influenced by an underlying resilience comprising reserve and compensation. Finding tailored interventions that target specific mechanisms of damage likely yields the most effective therapies.

\section{Introduction}

Cognitive impairment, including its extreme form dementia, is already a major health concern for older adults and looms as a public health disaster in the coming decades as a greater proportion of the population reaches older ages in both developed and developing

Address correspondence to: Dr. Thomas J. Montine, Department of Pathology, Stanford University, 300 Pasteur Dr., Stanford, CA 94305. E-mail: tmontine@stanford.edu

This work was supported by National Institutes of Health National Institute on Aging [Grant R01 AG021055], [Grant P50 AG016573], [Grant UF1 AG053983], [Grant P50 AG047366], and [Grant UF1 AG057707] and National Institute of Neurological Disorders and Stroke [Grant P50 NS062684].

https://doi.org/10.1124/pharmrev.120.000031. countries (Brookmeyer et al., 2011; GBD 2015 Mortality and Causes of Death Collaborators, 2016; GBD 2016 Dementia Collaborators, 2019). Success in decreasing the burden of other age-related diseases of the brain, such as stroke, despite an "aging" society has been achieved through effective lifestyle and therapeutic interventions. In contrast, the burden of neurodegenerative diseases that cause dementia or Parkinson disease (PD) has risen dramatically in the United States (Fig. 1). The ultimate goal of basic and clinical research being performed by thousands of investigators across the globe is to reduce the burden of cognitive impairment as we age. The purpose of this review is to provide perspective on the diseases, their molecular mechanisms, and mitigating processes for each that may be a target of interventions to reduce 
A

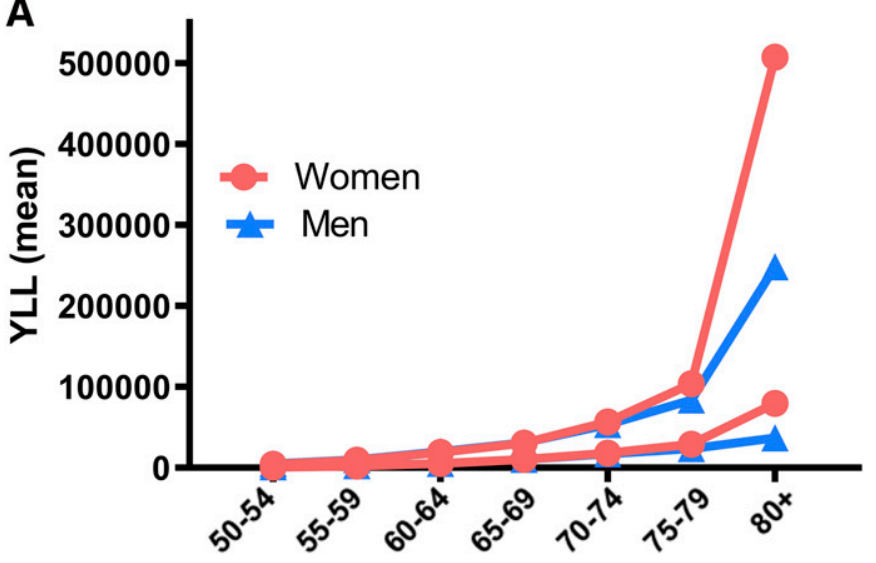

B

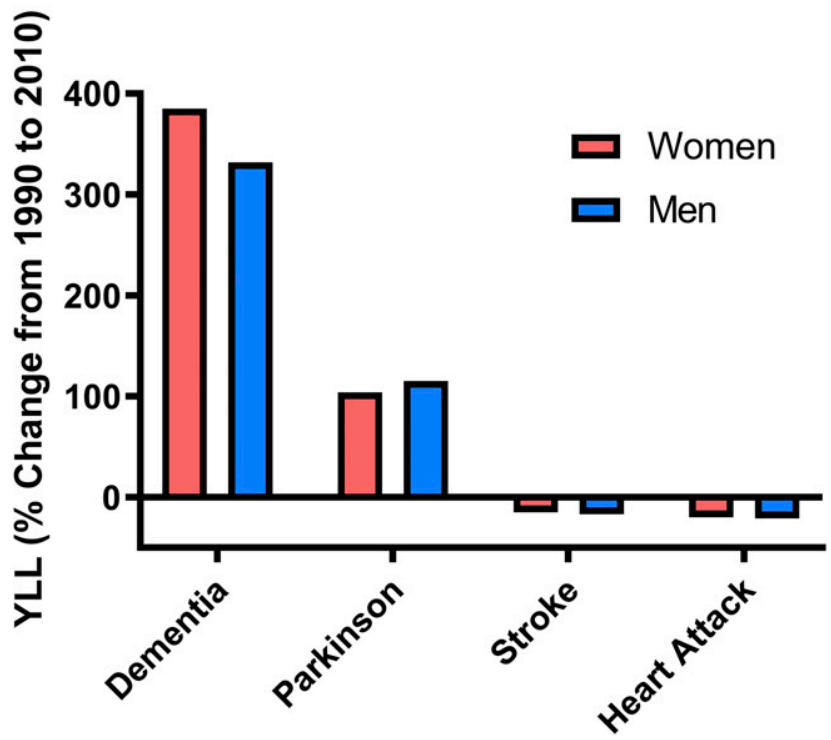

Fig. 1. (A) Graph of the mean years of life lost (YLL) to dementia in the United States by 5-year interval from 50- to 80+-years-old in 1990 and in 2010 stratified by sex. (B) Percent change in YLL in women and men of all ages between 1990 and 2010 for dementia, Parkinson disease, stroke (ischemic brain disease), and heart attack (ischemic heart disease). Data are from the Institute for Health Metrics and Evaluation (IHME_USA_GBD_2010_COD_1990_2010).

and hopefully to eventually eliminate cognitive decline in older age.

\section{Cognitive Impairment}

First, it is important to define terms so that we can be confident in our communication of concepts (Table 1). Disease is "any deviation from or interruption of the normal structure or function of any part, organ, or system (or any combination thereof) of the body that is manifest by a characteristic set of signs and symptoms..." (Dorland, 1981). A symptom is "any subjective
TABLE 1

List of key terms

Key Terms for Defining Cognitive Impairment Concepts

Disease

Symptom

Sign

Latency

Prodrome

Cognition

Cognitive decline

Preclinical

Mild cognitive impairment

Dementia

evidence of disease...", meaning that symptoms are reported by patients to their caregivers (Dorland, 1981). A sign is “...any objective evidence of disease...", meaning data collected by health care providers in a variety of ways, such as physical examination, imaging, and clinical laboratory tests (Dorland, 1981). It is critical to recognize that chronic disease produces signs and then symptoms; the stage during which chronic disease produces signs but not yet symptoms is called latency or latent disease. The stage of early symptomatic disease that does not fulfill all diagnostic criteria is called the prodrome (Fig. 2).

Cognition is "that operation of the mind ... (that) includes all aspects of perceiving, thinking, and remembering" and typically is measured in research settings by a wide array of neuropsychological tests that vary from broad assessments to focused evaluations of specific cognitive domains (Dorland, 1981). Cognitive decline is common as we age past 65 years and progresses insidiously, usually over years to decades. If neuropsychological test results are within normal ranges but neuroimaging or laboratory tests show evidence of a particular disease, such as Alzheimer disease $(\mathrm{AD})$, then this individual has latent disease, most commonly called preclinical AD (Sperling et al., 2011). When cognitive decline progresses to a state of objective impairment but is still short of full expression, this prodromal state is most commonly diagnosed as mild cognitive impairment (MCI) (Jack et al., 2011). When cognitive impairment becomes so severe as to interfere with what are called activities of daily living, such as eating, grooming, or navigating familiar surroundings, then these individuals with full expression of disease are diagnosed with dementia (McKhann et al., 2011). In summary, chronic disease develops progressively over years and is divided into three phases: latency, prodrome, and full expression of disease. In the case of chronic diseases that cause cognitive impairment, latency is most commonly called preclinical, and prodrome and full expression are most commonly diagnosed 


\begin{tabular}{|l|l|l|l|l|}
\hline \multirow{2}{*}{} & No Disease & \multicolumn{3}{|c|}{ Chronic Disease } \\
\cline { 2 - 5 } & \multicolumn{2}{|c|}{ Time } & \multicolumn{3}{c|}{ Progression } \\
\hline Signs & None & Some & More & Even More \\
\hline Symptoms & None & None & Some & More \\
\hline Stage & Health & Latent & Prodrome & Full Expression \\
\hline Designation & Normal & Pre-clinical & Mild Cognitive Impairment & Dementia \\
\hline
\end{tabular}

Fig. 2. Chart describing the relationships among signs and symptoms in chronic disease with focus on cognitive impairment and dementia.

as MCI and dementia, respectively. Although these stages form a tidy theoretical progression, the reality is that not everyone with latent disease (preclinical) progresses to prodrome (MCI), prodromal individuals (MCI) may progress to dementia but also may revert to latency (preclinical) or remain unchanged, and individuals with dementia still have progression of disease with further deterioration of function and thereby present a therapeutic opportunity despite being in the most advanced diagnostic category (Fig. 2) (McKhann et al., 2011; Cholerton et al., 2016).

\section{Pathologic Lesions Versus Biomarkers}

Research groups around the world have consistently shown that there are four prevalent diseases that commonly contribute to the signs and symptoms of cognitive impairment and dementia in older adults: $\mathrm{AD}$; vascular brain injury (VBI); Lewy body diseases (LBDs), which is a pathologic umbrella term that comprises the clinical diagnoses of PD and dementia with Lewy bodies (LBs) (DLB); and limbic-predominant age-related transactive response DNA-binding protein 43 (TDP43) encephalopathy (LATE) (Sonnen et al., 2007; White et al., 2016; Cykowski et al., 2017; Bennett et al., 2018; Nelson et al., 2019). We hasten to add that there are many more diseases that can cause cognitive impairment in adults, but these have pathologic lesions that are different in type and/or distribution from the four diseases listed above (e.g., chronic traumatic encephalopathy (CTE), prion diseases, and frontotemporal lobar degeneration; the latter two are relatively uncommon). Although there is clear contribution of traumatic brain injury and CTE to cognitive and behavioral changes in some specific groups, such as some professional athletes, the contribution of CTE to the public health challenge of cognitive impairment and dementia either directly or indirectly by increasing vulnerability to $\mathrm{AD}$ or LBD is an area of active investigation (Martland, 1928; Corsellis et al., 1973; McKee et al., 2016; Weiner et al., 2017; Stewart et al., 2019).

Intense work is underway to develop in vivo measures for the diseases that contribute to cognitive impairment so that the relative burden of each can be assessed in an individual. Unfortunately, the only tool currently available to comprehensively assess these diseases is brain autopsy, and that is why, at least for the time being, the field continues to rely on evaluation of pathologic lesions postmortem. Pathologic lesions are the characteristic structural changes in tissue used to 1) classify the disease or diseases present and 2) estimate the burden of each disease in an individual; these characteristic histopathologic features were designed to do the former and have been imperfectly adapted to do the latter (Postupna et al., 2015). The pathologic lesions for the four major diseases that can cause cognitive impairment and dementia in older individuals are: amyloid $\beta(\mathrm{A} \beta)$ plaques and neurofibrillary degeneration (typified by neurofibrillary tangles) for $\mathrm{AD}, \mathrm{LBs}$ and neurites for LBD, ischemic lesions varying from large territorial infarcts to microvascular lesions depending on the caliber of vessel involved for VBI, and limbic TDP-43 neuronal cytoplasmic inclusions with or without hippocampal sclerosis for LATE (Montine et al., 2012; Nelson et al., 2019) (Fig. 3). It is critical to acknowledge that, although they are characteristic of a particular disease and thereby presumably somehow related to disease-specific mechanisms, the pathologic lesions in tissue that are characteristic of a particular disease may be consequences rather than causes of damage (Hyman et al., 2012). Furthermore, it is unlikely for the diseases under consideration that the pathologic lesions are the anatomic basis of cognitive decline. Indeed, the anatomic basis for cognitive decline in all four of these diseases is regional neuronal dysfunction, synapse and dendrite loss, and neuron death (Terry and Katzman, 2001). Finally, some pathologic lesions are characteristic only within anatomic and clinical contexts. For example, neurofibrillary degeneration and TDP-43 neuron cytoplasmic inclusions may be observed in some forms of frontotemporal lobar degeneration (Riedl et al., 2014).

A major goal is to replace postmortem detection of pathologic lesions with in vivo assessments to aid in diagnosis and to serve as surrogates for assessing efficacy of therapeutics. Indeed, such in vivo tools will be essential to a precision medicine approach to cognitive impairment once disease-modifying therapies are achieved. Strong progress has been made in detecting pathologic lesions of $\mathrm{AD}$ using positron emission tomography for amyloid and, more recently, pathologic $\tau$ (Clark et al., 2012; Janelidze et al., 2020). Similar progress has been made with quantification of $\mathrm{A} \beta_{42}$ and $\tau$ isoforms in cerebrospinal fluid (Molinuevo et al., 2018). Both imaging and cerebrospinal fluid biomarkers of $\mathrm{AD}$ have been used widely in research settings. Newer technologies are now adapting cerebrospinal fluid assays to blood (Janelidze et al., 2020). Although many forms of VBI can be imaged exquisitely by magnetic resonance imaging (MRI), the strongest risk for the dementia syndrome appears to reside with microinfarcts whose individual size is below the limit of detection of most scanners. Imaging and laboratory 
biomarkers for LBD, LATE, and hippocampal sclerosis are under development.

\section{Diseases Versus Resilience}

Although it is relatively uncommon, individuals with dementia may have pathologic lesions of only $\mathrm{AD}, \mathrm{VBI}$, LBD, or LATE, demonstrating that each disease is sufficient to cause severe cognitive impairment. However, the much more common situation is comorbidity with the idiosyncratic combination of two or more of these diseases in an individual (White et al., 2016). Comorbidity increases with age; is influenced by multiple factors, including lifestyle choices and diet; and greatly complicates assignment of a specific disease to a specific set of signs and symptoms in an individual. Recognizing attributional uncertainty, often we use phrases like "AD and LBD contributed to dementia" for a person without the ability to determine how much of the severe functional impairment was due to $\mathrm{AD}$ or LBD or their potential interaction (Fig. 4). While adding significant complexity at the individual level, at the community level, population-attributable risk (PAR) estimates how much a particular disease contributes to dementia burden. By this approach, we first estimated that the PAR for AD is approximately $45 \%$, VBI is approximately $33 \%$, and LBD is about $10 \%$, leaving about $12 \%$ of dementia not readily explained in a cohort of men and women in their mid-80s of mostly European descent living in urban and suburban settings (Sonnen et al., 2007). We speculated that there may be other disease(s) not appreciated at the time or that a small subset of the population was especially vulnerable to functional impairment from very low levels of these three diseases. Other groups have replicated our findings, although point estimates of attributable risk vary
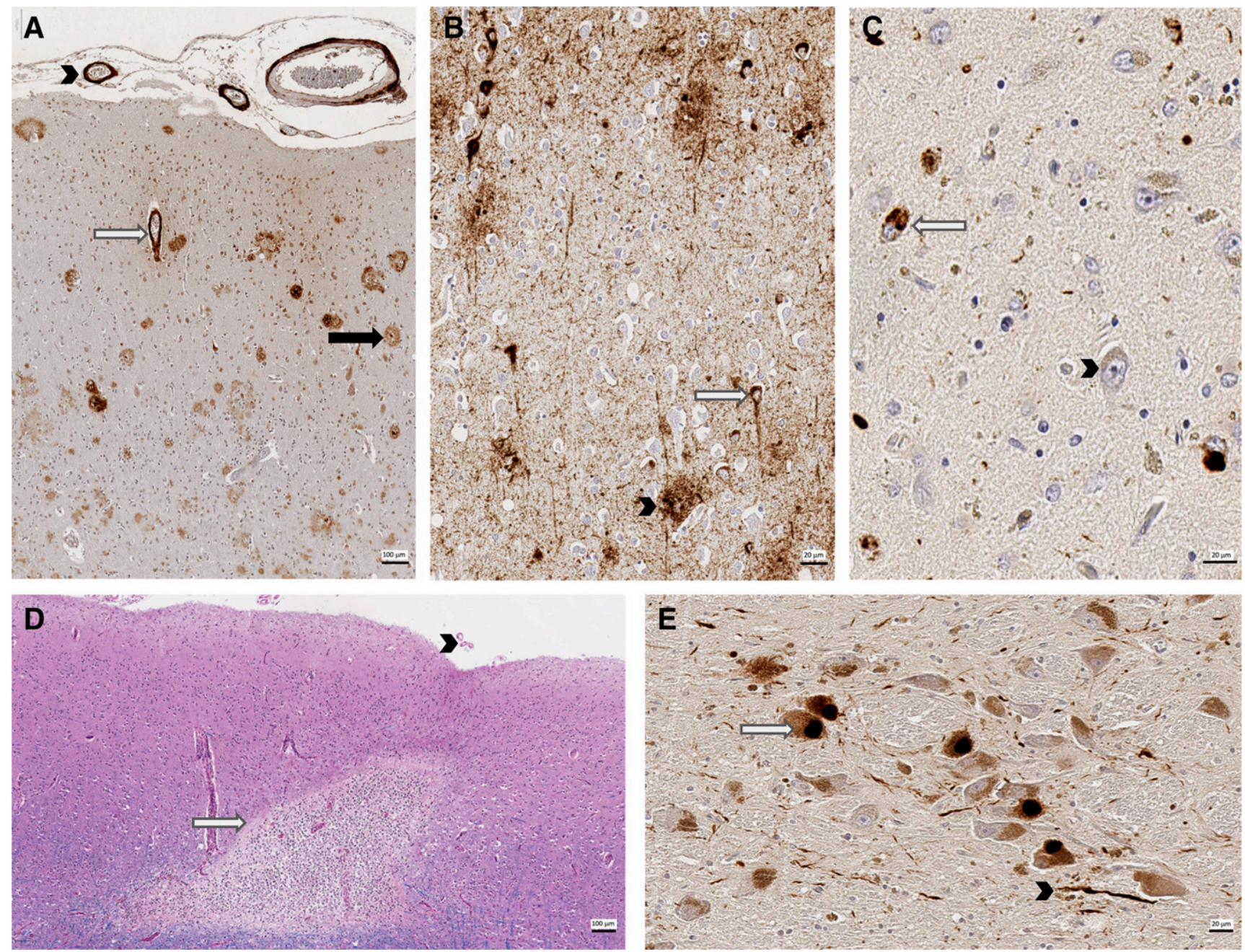

Fig. 3. Photomicrographs of pathologic lesions that are characteristic of Alzheimer disease [(A) senile plaques (black arrow), cerebral amyloid angiopathy in cerebral cortex (white arrow), and cerebral amyloid angiopathy in leptomeninges delineating lateral surface (arrowhead) and (B) neurofibrillary degeneration in transentorhinal cortex (white arrow) and neuritic plaques (arrowhead)]. (C) Limbic-predominant age-related TDP-43 encephalopathy (white arrow) in hippocampus along with a lipofuscin-laded neuron devoid of TDP-43 inclusions (arrowhead). (D) Microinfarct in cerebral cortex (white arrow) with leptomeninges delineating lateral surface (arrowhead). (E) Lewy bodies in the substantia nigra (white arrow) of a patient with Parkinson disease with Lewy neurites (arrowhead). Methods were immunohistochemistry for (A) A $\beta \times 10$, (B) paired helical filament $\tau$ $\times 30$, (C) phospho-TDP-43 $\times 40$, and (E) phospho129- $\alpha$-synuclein $\times 40$, or (D) hematoxylin and eosin plus luxol fast blue $\times 8$. Phospho, phosphorylated. 

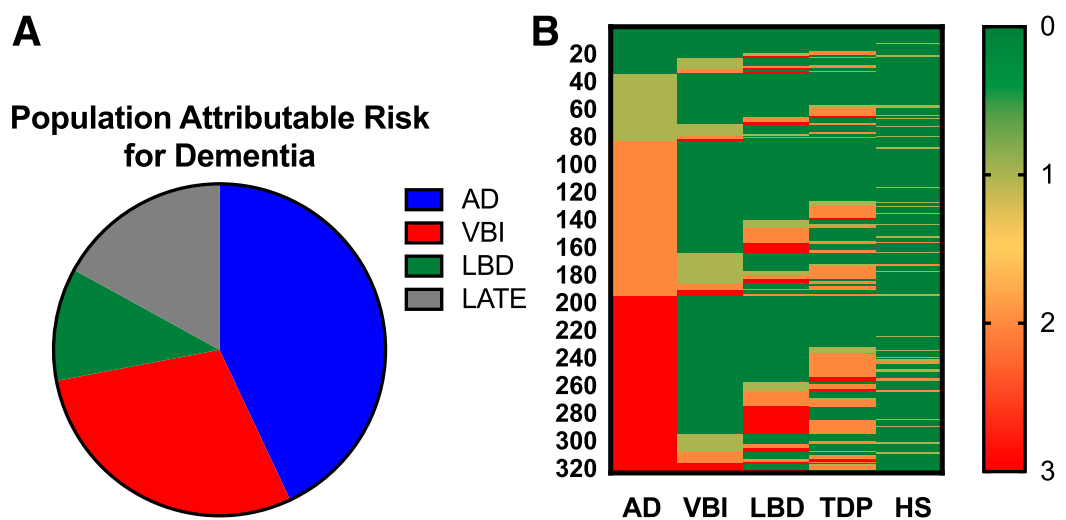

Fig. 4. (A) Pie chart of avg. PAR for dementia calculated from the papers cited in text. (B) Heatmap of the burden of disease in individuals who participated in The 90+Study. Each row contains data from 1 of 322 individuals. Data are encoded as no/minimal- (0), low- (1), medium- (2), or high- (3) level pathologic changes of AD, VBI, LBD, or TDP-43 neuronal cytoplasmic inclusions (TDP); hippocampal sclerosis (HS) was encoded as none (0), unilateral (1), or bilateral (2).

with cohort (Boyle et al., 2019), and expanded to include attributable risk estimates for LATE (not recognized at the time of our original study). One group calculated the 95\% confidence interval for attributable risk in two different cohorts: $32 \%-47 \%$ for $\mathrm{AD}, 17 \%-32 \%$ for $\mathrm{VBI}$, 8\%-16\% for LBD, and 13\%-22\% for LATE (Nelson et al., 2019).

The issue of comorbidity is critically important to interpreting clinical trials that rely on diagnostic and/or neuropsychological endpoints only. These many studies and trials are inherently limited by unknown amounts of comorbid disease among the trial participants. Imagine a clinical trial for a novel agent that targets an $\mathrm{AD}$-specific mechanism powered for an expected effect size. Now consider that one-third to one-half of the trial cohort, depending on the selection criteria, likely have at least two diseases contributing to cognitive impairment and that the quality and quantity of comorbidity varies extensively among individuals. Such trials, of which there have been many, are destined to fail, which they all have (Arvanitakis et al., 2019; Veitch et al., 2019; Tolar et al., 2020). These concerns are the main rationale behind the several major efforts to develop reproducible in vivo biomarkers for each of the four different diseases that commonly contribute to cognitive impairment and dementia.

Although it seems straightforward that disease leads to signs and symptoms, there are clear examples when this does not occur. For example, somewhere between $5 \%$ and $15 \%$ of volunteers from community cohorts were living independently and were cognitively normal proximate to death despite having high-level pathologic changes of $\mathrm{AD}, \mathrm{VBI}$, or $\mathrm{LBD}$; in contrast, almost all individuals with hippocampal sclerosis were cognitively impaired (White et al., 2016; Latimer et al., 2017). Pathologic changes, whether determined by autopsy or neuroimaging, are highly characteristic of a disease but may be only loosely or indirectly related to the extent of relevant damage. Nevertheless, using these goldstandard measures of specific disease, the uncoupling of pathologic lesions from their usual clinical consequences must be attributed to some other set of processes that mitigate the signs and symptoms usually caused by damage; this set of processes is called resilience. Resilience is a deceptively simple concept that is the net of at least two processes: reserve capacity and compensation. Importantly, resilience does not limit damage or the characteristic pathologic lesions; however, resilience

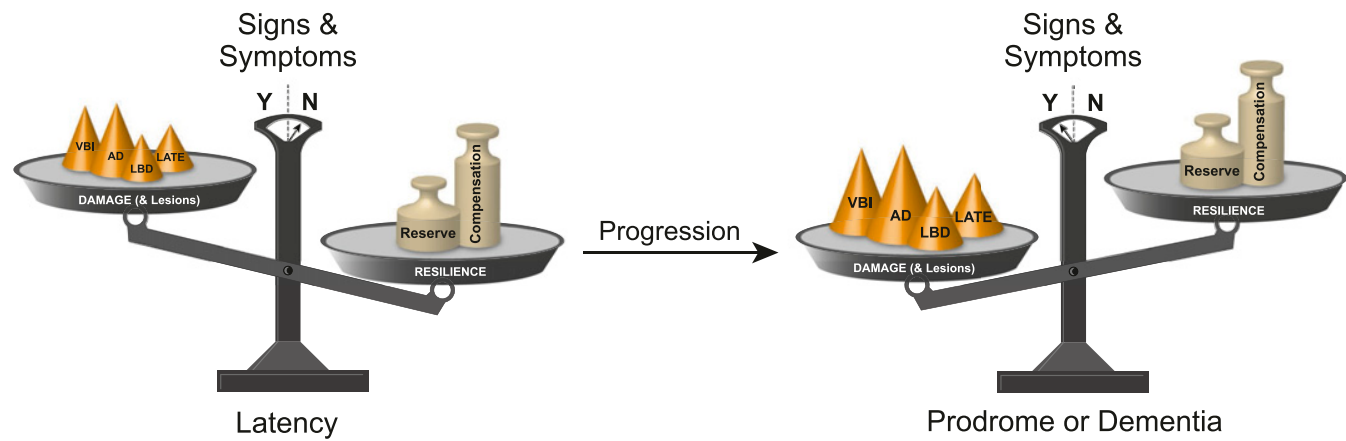

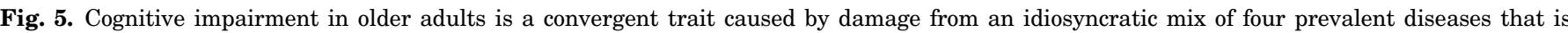

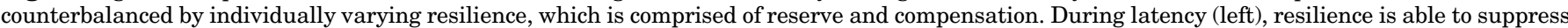

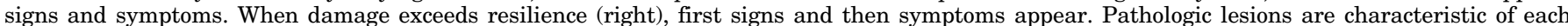
disease and may or may not contribute to damage. 
does reduce the signs and symptoms expected from damage (Fig. 5).

Reserve is excess capacity developed or accrued over a lifetime akin to military reserves that may be brought into action at time of emergency. A more biologic example may be the number of neurons or synapses in regions of brain. Some aspects of reserve capacity may be static (number of neurons), and others may be dynamic (synaptic density or neural systems redundancy). It is likely that many interacting factors contribute to reserve capacity, including (epi)genetics, development, education, occupation, training, lifestyle choices, health, diet, and others. An example is the lifestyle choice of regular exercise that, among many beneficial effects to the body, increases neurotrophic factor release and synapse density (Rothman and Mattson, 2013; Lourenco et al., 2019). Compensation is the maintenance of function by counterbalance, like increasing heart rate to counterbalance orthostatic hypotension. We envision compensation for cognitive function as intrinsic or extrinsic. Intrinsic (physiologic) compensation is remodeling or functional adaptation in response to disease. An example would be recruitment of redundant or alternative neural circuits to assist in memory formation after damage to the hippocampus (Canter et al., 2016). Physiologic compensation eventually is overwhelmed by ongoing damage and ultimately fails to counterbalance it, leading to clinical deterioration. Lastly, by analogy with other organs, physiologic compensation is likely accompanied by some tradeoff or cost and may even become maladaptive over time. Examples of extrinsic compensation are assistance and support by a family member, caregiver, or robotic assistant.

\section{Damage Versus Resistance}

Damage leads to signs and symptoms of cognitive impairment and dementia in older adults, with varying resilience among individuals complicating a simple direct relationship between the two. How does chronic disease cause damage to the brain? We espouse a model for cognitive impairment and dementia that is similar to the "response-to-injury" hypothesis proposed for atherosclerosis (Ross, 1986). In this model (Fig. 6), diseasespecific stressor(s) or injury stimulate response(s) from the surrounding tissue that initially may be beneficial by repairing injury or suppressing further stress; however, over time, response to stressors itself can become deleterious and thus indirectly elicit new or additional forms of injury and stress. When this occurs, injury/response sets up a feed-forward cycle that causes extensive damage; the classic example of this type of feed-forward cycle is the response to injury that occurs with protracted infection by Mycobacterium tuberculosis and ultimately destruction of large areas of lung. Damage to some or all tissue elements is the net effect of

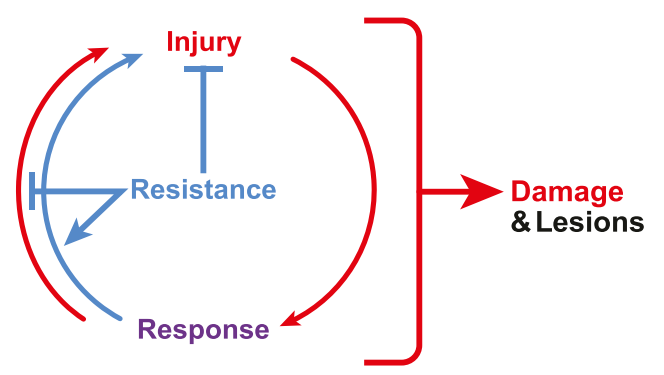

Fig. 6. Consideration of the "response-to-injury" model (Ross, 1986) in cognitive impairment. Damage and attendant pathologic lesions are the product of the combined impact of a cycle of disease-specific stressor(s) or injury and response to injury. Despite beneficial aspects, the response may also elicit additional stress. Resistance limits damage (and thereby lesions) both by suppressing injury and by modulating the response: suppressing maladaptive responses and/or promoting adaptive responses (e.g., repair).

injury/response and may be overlapping or completely distinct among the four major diseases that cause cognitive impairment and dementia. For example, both $\mathrm{AD}$ and LBD are hypothesized to injure primarily synapses with an accompanying glial response that eventually contributes to further injury culminating in neuron death. In contrast, VBI is ischemic injury that to varying degrees damages all tissue elements and is not focused on synapses (Montine and Hulette, 1996; Sonnen et al., 2007).

The dominant hypothesis for damage in $\mathrm{AD}$ is called the amyloid cascade hypothesis, which proposes that endoproteolytic products of the amyloid precursor protein called $\mathrm{A} \beta$ peptides are the causes of synaptic/ neuronal injury (Hardy, 2017). This hypothesis is strongly supported by autosomal dominant mutations that are sufficient to cause $\mathrm{AD}$ in middle-aged adults and, by extensive investigation of experimental models, mostly transgenic mice (Schellenberg and Montine, 2012). Genetic risk in large cohort studies most strongly implicates the $\varepsilon 4$ allele of $A P O E$; the apoE isoforms have multiple biologic functions, including trafficking of $\mathrm{A} \beta$ but also neuron repair and modulation of the innate immune response in brain (Arendt et al., 1997; Keene et al., 2011; Mahley, 2016). Many other less strongly associated genetic risk loci also implicate the immune response (Kunkle et al., 2019). Together, these data support the view that $\mathrm{A} \beta$-induced injury elicits an immune response that may be initially beneficial but when protracted may trigger further injury to synapses and ultimately neurons. The other major pathologic feature of $\mathrm{AD}$, neurofibrillary degeneration, has long been proposed to be the consequence of a deleterious response to $\mathrm{A} \beta$-induced injury (Gallardo and Holtzman, 2019); however, only partially overlapping anatomic distribution of these two pathologic features is a challenge to this perhaps overly simplistic scenario. Although the amyloid cascade hypothesis is dominant, other hypotheses for the mechanisms of injury in $\mathrm{AD}$ include prion-like activity of $\mathrm{A} \beta$ and pathologic $\tau$, mitochondrial dysfunction, oxidative damage, and many others (Sonnen et al., 2008; Goedert, 2015; Kozlov et al., 2017). However, none 
have yet to fully reconcile the known age, genetic, and environmental risk factors for $\mathrm{AD}$.

LBs and their attendant neurites are intraneuronal inclusions that contain numerous proteins-most notably $\alpha$-synuclein, a presynaptic protein strongly linked by genetic mutations and triplication to PD (Singleton et al., 2017). PD really is a clinico-pathologic entity, meaning that itnis defined by characteristic clinical features and pathologic features; the former is a constellation of motor abnormalities, and the latter is LBs in brainstem nuclei. LBs in other regions of brain, namely limbic structures and cerebral cortex, are the pathologic features of DLB, which has primarily cognitive and behavioral rather than motor signs and symptoms (McKeith et al., 2017); PD and DLB form a clinical continuum grouped as LBD. Dementia from LBD also has been linked to the $\varepsilon 4$ allele of $A P O E$ (Tsuang et al., 2013), a finding recently supported by animal models of "synucleinopathy" (Davis et al., 2020; Zhao et al., 2020). The most common genetic risk for PD is heterozygosity for mutations in $G B A$, which encodes glucocerebrosidase (Mata et al., 2008; Sidransky et al., 2009). Genetic association and experimental models implicate altered neuronal vesicle handling, lysosomal function, diminished mitochondrial function, proteostasis, and inflammation in the damage caused to synapses, dendrites, and neurons in LBD (Goedert, 2015; Blauwendraat et al., 2020).

VBI encapsulates a somewhat bewildering array of terms used to describe damage to brain from ischemic injury. It is most useful to consider location and caliber of the blood vessel involved when considering the cognitive consequences of VBI. Large caliber vessels affected by atherosclerosis, other thromboemboli, vasculitis, or a long list of other vascular diseases can cause ischemic damage to large territories of brain (e.g., an infarct in the territory of the middle cerebral artery). When sufficient cerebral cortex is damaged or if strategic structures, such as the hippocampus, are involved, then cognitive impairment and dementia ensue. Importantly, large territorial infarcts produce signs and symptoms of stroke and can lead to episodic cognitive decline (Iadecola et al., 2019). In contrast, diseaseafflicting small vessels, most importantly systolic hypertension and diabetes mellitus, yield microscopic lesions in the cerebrum and a progressive dementia syndrome that broadly overlaps with the other three neurodegenerative diseases under discussion (Sonnen et al., 2009; Wang et al., 2009). It remains unclear whether the anatomic basis for cognitive impairment from small-vessel disease is simply the integral of microscopic ischemic injury over time, more widespread capillary dysfunction, or both.

LATE is a more recent concept of damage focused on limbic structures of older adults that is characterized by TDP-43 neuron cytoplasmic inclusions often with hippocampal sclerosis (Nelson et al., 2019). TDP-43, encoded by TARDBP (Ou et al., 1995), binds to RNA and DNA and to other proteins and regulates transcription and translation (Cohen et al., 2011). TDP-43 is expressed by most cells where it is localized mostly in nuclei; in disease states, the TDP-43 is phosphorylated and translocated to the cytoplasm (Neumann et al., 2006). Neurons in the amygdala, hippocampus, and then cerebral cortex show apparent graded vulnerability or perhaps cell-to-cell transmission of this "TDP-43-opathy," which often but not always is accompanied by profound neurodegeneration and gliosis in the pyramidal neuron layer of the hippocampus, called hippocampal sclerosis (Dickson et al., 1994).

Resistance is the net effect of mitigating factors that limit damage either by suppressing injury, promoting beneficial response, or limiting deleterious response. Resistance reduces damage (and its disease-specific pathologic lesions) and thereby signs and symptoms. Therefore, both resistance and resilience limit signs and symptoms, but resistance achieves this by suppressing damage, whereas resilience achieves this by counterbalancing damage. Perhaps the best example of a known resistance factor is the isoform encoded by the $\varepsilon 2$ allele of $A P O E$, apoE2. Homozygosity for APOE $\varepsilon 2$ is associated with reduced pathologic lesions of $\mathrm{AD}$, and the signs and symptoms of $\mathrm{AD}$ are very rare in people with this resistant genotype (Reiman et al., 2020). A number of experimental models support apoE2 as a resistance factor that suppresses injury, enhances neuron repair, and suppresses neurotoxic immune response (Maezawa et al., 2006a,b; Huang and Mahley, 2014; Chung et al., 2016; Zhao et al., 2016; Huang et al., 2017). Another example of a resistance factor is the $A P O E$ Christchurch mutation; homozygosity for this rare variant conferred apparent resistance to a person with a disease-causing presenilin 1 mutation (Arboleda-Velasquez et al., 2019).

\section{Time}

It is important to consider time over two frames: decades and hours. The prevalent diseases that contribute to cognitive impairment and dementia often are called "age-related" in the sense that each is exponentially more prevalent as a population ages, and advancing age is the strongest risk factor in an individual. There is substantial evidence that neurodegenerative disease starts one or two decades before the earliest onset of symptoms. The processes that are influenced by the biologic changes that accompany advancing age in older adults are not clear, but we hypothesize that injury, response to injury, resistance, reserve, and compensation are each candidates. By this hypothesis, the outcomes of these processes-damage, lesions, signs, and symptoms-need not be directly influenced by age.

The other time frame to consider is hours, as in the influence of circadian rhythm. Indeed, "sundowning," or 
a cyclic delirium-like condition at the end of the day, is commonly reported by older individuals challenged by these diseases or by their caregivers (Boronat et al., 2019). Given these temporal relationships, we speculate that sundowning is related to diurnal fluctuations in processes of resilience, most likely compensation. Circadian rhythms as well as the quantity and quality of sleep also may be more directly tied to some aspects of neuronal injury, such as the daily clearance of $\mathrm{A} \beta$ peptides, forms of which are proposed to cause neuronal injury (Musiek et al., 2015; Leng et al., 2019).

In addition to being age-related, the four prevalent diseases that contribute to cognitive impairment and dementia also are considered chronic because at the organism level their signs and symptoms develop over decades. We hasten to stress that at the molecular and cellular levels damage might accrue over decades, as is thought to be the case in AD and LBD. Alternatively, damage might occur acutely, and it is the integral of episodic acute injury at the molecular and cellular level over time that gives the clinical impression of chronicity, as is thought to occur with some forms of VBI.

\section{Interventions}

Cognitive impairment in older adults is a convergent trait that is a balance between damage by an idiosyncratic mix of four prevalent diseases and mitigation by individually varying processes of resistance and resilience. Introduction of experimental therapeutics into this complexity is clearly fraught with difficulties. For example, it should now be clear that clinical trials based on clinical diagnosis or neuropsychological test results are actually only investigations of a drug's impact on a syndrome, with the underlying diseases unknowingly varying among participants. Perhaps this is the correct design for a therapeutic that is thought to address a pervasive mechanism of brain aging, but this design is programmed to fail when targeting a disease-specific mechanism like $\mathrm{A} \beta$ accumulation. Interventions often are cast as "disease-modifying" or not; however, this is an ambiguous term because, as discussed above, components of disease include injury, response, resistance, and resilience. Broadly speaking, interventions have focused on 1) relief of symptoms without slowing or stopping further damage, 2) prevention or suppression of damage by targeting a specific mechanism of injury or maladaptive response, and 3) attempts to repair accumulated damage in the hope of restoring lost function.

Successful therapeutics for neurodegenerative diseases are mostly in the first group: agents that relieve symptoms without apparent impact on ongoing damage. Indeed, acetylcholinesterase inhibitors in $\mathrm{AD}$ and dopamine replacement in PD are examples of therapeutics that enhance resilience, likely intrinsic compensation, and thereby reduce symptoms without altering the underlying progress of damage. In the case of acetylcholinesterase inhibition, although initially counterbalancing the damage from injury/response in $\mathrm{AD}$, eventually this class of drug fails to bring benefit. Dopamine replacement therapy also brings symptomatic relief to patients with PD, but eventually the effectiveness wanes from advancement of underlying injury/response and can lead to the maladaptive consequence of drug-induced dystonia. Extrinsic compensation can also be an effective target of interventions, such as increased social interaction for patients with cognitive decline or assist devices like timed pill dispensers to offset in part memory deficits.

Realization of the underlying complexity of cognitive decline as we age has been the major impetus to develop biomarkers to comprehensively diagnose the four major diseases during life and to evaluate the burden of each disease in an individual and thereby stratify individuals into disease- or mechanism-specific subgroups. Imaging and biochemical biomarkers for $\mathrm{AD}$ have advanced greatly, are increasingly applied in clinical trials, and have even been recommended as the primary endpoint in a "fast to fail" approach in early-phase clinical trials (Sieber et al., 2014). Unfortunately, so far there is limited progress for robust biomarkers for the other common neurodegenerative diseases: LBD, hippocampal sclerosis, and LATE.

Another approach is to limit cohorts to individuals with a shared common strong genetic risk factor, such as $A P O E \& 4$ in sporadic $\mathrm{AD}$ or $G B A$ mutations in PD. The extreme example of this approach is the Dominantly Inherited Alzheimer Network Trials Unit trial of $\mathrm{A} \beta$-lowering therapeutics in presymptomatic individuals who carry disease-causing mutations in presenilin 1 proximate to the average age of dementia onset in their family (Mills et al., 2013). This is a critical trial because such patients have "pure" $\mathrm{AD}$ with very limited comorbidities (because of younger age) compared with the much more common sporadic disease. Moreover, it is perhaps the clearest example of an attempt to prevent or suppress damage by targeting a proposed mechanism of injury in $\mathrm{AD}$. Unfortunately, these investigators recently announced that phase $2 / 3$ trial results for two different $\mathrm{A} \beta$ IgG antibodies failed to achieve the primary endpoint of significant difference between drug and placebo on a composite cognitive score (https:// www.alzforum.org/news/research-news/topline-resultfirst-dian-tu-clinical-trial-negative-primary). Smallmolecule approaches are now underway for individuals with PD who carry a $G B A$ mutation or a mutation in the leucine-rich repeat kinase 2 gene (Schneider and Alcalay, 2020), and we should expect more focused clinical trials on cohorts of individuals stratified by common genetic risk or by biomarker selection.

We close with an example of success. As discussed, the pathophysiologic processes that underlie formation of microvascular lesions, which signify ischemic damage at the capillary level (microvascular brain injury), are 
a major contributor to dementia in older adults with an odds ratio and PAR comparable with AD (Sonnen et al., 2007; Nelson et al., 2019). The major risk factors for microvascular brain injury are systolic hypertension and diabetes mellitus (Sonnen et al., 2009; Wang et al., 2009), and their imperfect neuroimaging correlates are white matter lesions identified by MRI (Longstreth et al., 2009); remember, microvascular lesions are too small to be directly observed by standard MRI techniques. Based in part on these very consistent results from brain autopsy studies, the Systolic Blood Pressure Intervention Trial-Memory and Cognition in Decreased Hypertension study tested whether more aggressive treatment of systolic blood pressure might prevent cognitive decline (Williamson et al., 2019). Systolic Blood Pressure Intervention Trial-Memory and Cognition in Decreased Hypertension also reported reduced accumulation of white matter lesion in the treatment group among a subset of trial participants who had MRI (Kjeldsen et al., 2018). This is the first trial to demonstrate an intervention that significantly reduces the occurrence of MCI as well as the combined occurrence of MCI or dementia. The trial did not detect an impact on the occurrence of dementia, but that may be due in part to the relative short period of study as supported by many observational studies that show a much greater impact on later-life cognitive function by midlife hypertension and its treatment (Farmer et al., 1990; Wang et al., 2009; Launer et al., 2011; Shah et al., 2012; Gelber et al., 2013).

This encouraging clinical trial shows that interventions that target the mechanisms of damage that underlie pathologic features of one of the four major diseases can limit cognitive decline in older adults. We hopefully anticipate future "disease-modifying" interventions for $A D, L B D$, and LATE.

\section{Concluding Remarks}

Cognitive impairment, a major public health concern for older adults, is a convergent trait that is a balance between damage by an idiosyncratic mix of four prevalent diseases and mitigation by individually varying processes of resistance and resilience. Although there is consensus that the anatomic site of cognitive impairment is synapses and neurons, there is no consensus yet on the mechanism(s) of injury/response by neurodegenerative diseases nor on interventions that suppress damage. Therapeutic successes for neurodegenerative diseases so far have been achieved largely by enhancing resilience with emerging hope for preventing cognitive impairment from VBI.

\section{Acknowledgments}

We wish to thank Norm Cyr for his expert artwork and Kathleen Montine for editorial assistance.

\section{Authorship Contributions}

Participated in research design: Montine.

Conducted experiments: Bukhari.

Performed data analysis: White.

Wrote or contributed to the writing of the manuscript: Montine, Bukhari, White.

\section{References}

Arboleda-Velasquez JF, Lopera F, O’Hare M, Delgado-Tirado S, Marino C, Chmielewska N, Saez-Torres KL, Amarnani D, Schultz AP, Sperling RA, et al. (2019) Resistance to autosomal dominant Alzheimer's disease in an APOE3 Christchurch homozygote: a case report. Nat Med 25:1680-1683.

Arendt T, Schindler C, Brückner MK, Eschrich K, Bigl V, Zedlick D, and Marcova L (1997) Plastic neuronal remodeling is impaired in patients with Alzheimer's disease carrying apolipoprotein epsilon 4 allele. J Neurosci 17:516-529.

Arvanitakis Z, Shah RC, and Bennett DA (2019) Diagnosis and management of dementia: review. JAMA 322:1589-1599.

Bennett DA, Buchman AS, Boyle PA, Barnes LL, Wilson RS, and Schneider JA (2018) Religious orders study and rush memory and aging project. J Alzheimers Dis 64 (Suppl 1):S161-S189.

Blauwendraat C, Nalls MA, and Singleton AB (2020) The genetic architecture of Parkinson's disease. Lancet Neurol 19:170-178.

Boronat AC, Ferreira-Maia AP, and Wang YP (2019) Sundown syndrome in older persons: a scoping review. J Am Med Dir Assoc 20:664-671.e5.

Boyle PA, Yu L, Leurgans SE, Wilson RS, Brookmeyer R, Schneider JA, and Bennett DA (2019) Attributable risk of Alzheimer's dementia attributed to age-related neuropathologies. Ann Neurol 85:114-124.

Brookmeyer R, Evans DA, Hebert L, Langa KM, Heeringa SG, Plassman BL, and Kukull WA (2011) National estimates of the prevalence of Alzheimer's disease in the United States. Alzheimers Dement 7:61-73.

Canter RG, Penney J, and Tsai LH (2016) The road to restoring neural circuits for the treatment of Alzheimer's disease. Nature 539:187-196.

Cholerton B, Larson EB, Quinn JF, Zabetian CP, Mata IF, Keene CD, Flanagan M, Crane PK, Grabowski TJ, Montine KS, et al. (2016) Precision medicine: clarity for the complexity of dementia. Am J Pathol 186:500-506.

Chung WS, Verghese PB, Chakraborty C, Joung J, Hyman BT, Ulrich JD, Holtzman DM, and Barres BA (2016) Novel allele-dependent role for APOE in controlling the rate of synapse pruning by astrocytes. Proc Natl Acad Sci USA 113: 10186-10191.

Clark CM, Pontecorvo MJ, Beach TG, Bedell BJ, Coleman RE, Doraiswamy PM, Fleisher AS, Reiman EM, Sabbagh MN, Sadowsky CH, et al.; AV-45-A16 Study Group (2012) Cerebral PET with florbetapir compared with neuropathology at autopsy for detection of neuritic amyloid- $\beta$ plaques: a prospective cohort study. Lancet Neurol 11:669-678.

Cohen TJ, Lee VM, and Trojanowski JQ (2011) TDP-43 functions and pathogenic mechanisms implicated in TDP-43 proteinopathies. Trends Mol Med 17:659-667.

Corsellis JA, Bruton CJ, and Freeman-Browne D (1973) The aftermath of boxing. Psychol Med 3:270-303.

Cykowski MD, Powell SZ, Schulz PE, Takei H, Rivera AL, Jackson RE, Roman G, Jicha GA, and Nelson PT (2017) Hippocampal sclerosis in older patients: practical examples and guidance with a focus on cerebral age-related TDP-43 with sclerosis. Arch Pathol Lab Med 141:1113-1126.

Davis AA, Inman CE, Wargel ZM, Dube U, Freeberg BM, Galluppi A, Haines JN, Dhavale DD, Miller R, Choudhury FA, et al. (2020) APOE genotype regulates pathology and disease progression in synucleinopathy. Sci Transl Med 12: eaay3069.

Dickson DW, Davies P, Bevona C, Van Hoeven KH, Factor SM, Grober E, Aronson MK, and Crystal HA (1994) Hippocampal sclerosis: a common pathological feature of dementia in very old ( $>$ or $=80$ years of age) humans. Acta Neuropathol 88: $212-221$.

Dorland WAN (1981) Dorland's Illustrated Medical Dictionary, 26th ed, W. B. Saunders Co., Philadelphia.

Farmer ME, Kittner SJ, Abbott RD, Wolz MM, Wolf PA, and White LR (1990) Longitudinally measured blood pressure, antihypertensive medication use, and cognitive performance: the Framingham Study. J Clin Epidemiol 43:475-480.

Gallardo G and Holtzman DM (2019) Amyloid- $\beta$ and tau at the Crossroads of Alzheimer's disease. Adv Exp Med Biol 1184:187-203.

GBD 2015 Mortality and Causes of Death Collaborators (2016) Global, regional, and national life expectancy, all-cause mortality, and cause-specific mortality for 249 causes of death, 1980-2015: a systematic analysis for the Global Burden of Disease Study 2015 [published correction appears in Lancet (2017) 389:e1]. Lancet 388: $1459-1544$

GBD 2016 Dementia Collaborators (2019) Global, regional, and national burden of Alzheimer's disease and other dementias, 1990-2016: a systematic analysis for the Global Burden of Disease Study 2016. Lancet Neurol 18:88-106.

Gelber RP, Ross GW, Petrovitch H, Masaki KH, Launer LJ, and White LR (2013) Antihypertensive medication use and risk of cognitive impairment: the HonoluluAsia Aging Study. Neurology 81:888-895

Goedert M (2015) NEURODEGENERATION. Alzheimer's and Parkinson's diseases: the prion concept in relation to assembled $\mathrm{A} \beta$, tau, and $\alpha$-synuclein. Science 349: 1255555

Hardy J (2017) The discovery of Alzheimer-causing mutations in the APP gene and the formulation of the "amyloid cascade hypothesis". FEBS J 284:1040-1044.

Huang Y and Mahley RW (2014) Apolipoprotein E: structure and function in lipid metabolism, neurobiology, and Alzheimer's diseases. Neurobiol Dis 72:3-12.

Huang YA, Zhou B, Wernig M, and Südhof TC (2017) ApoE2, ApoE3, and ApoE4 differentially stimulate APP transcription and A $\beta$ secretion. Cell 168:427-441.e21. 
Hyman BT, Phelps CH, Beach TG, Bigio EH, Cairns NJ, Carrillo MC, Dickson DW, Duyckaerts C, Frosch MP, Masliah E, et al. (2012) National Institute on AgingAlzheimer's Association guidelines for the neuropathologic assessment of Alzheimer's disease. Alzheimers Dement 8:1-13.

Iadecola C, Duering M, Hachinski V, Joutel A, Pendlebury ST, Schneider JA, and Dichgans M (2019) Vascular cognitive impairment and Dementia: JACC scientific expert panel. $J$ Am Coll Cardiol 73:3326-3344

Jack CR Jr, Albert MS, Knopman DS, McKhann GM, Sperling RA, Carrillo MC, Thies B, and Phelps CH (2011) Introduction to the recommendations from the National Institute on Aging-Alzheimer's Association workgroups on diagnostic guidelines for Alzheimer's disease. Alzheimers Dement 7:257-262.

Janelidze S, Mattsson N, Palmqvist S, Smith R, Beach TG, Serrano GE, Chai X, Proctor NK, Eichenlaub U, Zetterberg H, et al. (2020) Plasma P-tau181 in Alzheimer's disease: relationship to other biomarkers, differential diagnosis, neuropathology and longitudinal progression to Alzheimer's dementia. Nat Med 26: 379-386.

Keene CD, Cudaback E, Li X, Montine KS, and Montine TJ (2011) Apolipoprotein E isoforms and regulation of the innate immune response in brain of patients with Alzheimer's disease. Curr Opin Neurobiol 21:920-928.

Kjeldsen SE, Narkiewicz K, Burnier M, and Oparil S (2018) Intensive blood pressure lowering prevents mild cognitive impairment and possible dementia and slows development of white matter lesions in brain: the SPRINT Memory and Cognition IN Decreased Hypertension (SPRINT MIND) study. Blood Press 27:247-248.

Kozlov S, Afonin A, Evsyukov I, and Bondarenko A (2017) Alzheimer's disease: as it was in the beginning. Rev Neurosci 28:825-843.

Kunkle BW, Grenier-Boley B, Sims R, Bis JC, Damotte V, Naj AC, Boland A, Vronskaya M, van der Lee S.J, Amlie-Wolf A, et al.; Alzheimer Disease Genetics Consortium (ADGC); European Alzheimer's Disease Initiative (EADI); Cohorts for Heart and Aging Research in Genomic Epidemiology Consortium (CHARGE); Genetic and Environmental Risk in AD/Defining Genetic, Polygenic and Environmental Risk for Alzheimer's Disease Consortium (GERAD/PERADES) (2019) Genetic meta-analysis of diagnosed Alzheimer's disease identifies new risk loci and implicates $\mathrm{A} \beta$, tau, immunity and lipid processing [published correction appears in Nat Genet (2019) 51:1423-1424]. Nat Genet 51:414-430.

Latimer CS, Keene CD, Flanagan ME, Hemmy LS, Lim KO, White LR, Montine KS, and Montine TJ (2017) Resistance to Alzheimer disease neuropathologic changes and apparent cognitive resilience in the nun and Honolulu-Asia aging studies. $J$ Neuropathol Exp Neurol 76:458-466.

Launer LJ, Hughes TM, and White LR (2011) Microinfarcts, brain atrophy, and cognitive function: the Honolulu Asia Aging Study Autopsy Study. Ann Neurol 70: $774-780$.

Leng Y, Musiek ES, Hu K, Cappuccio FP, and Yaffe K (2019) Association between circadian rhythms and neurodegenerative diseases. Lancet Neurol 18:307-318.

Longstreth WT Jr, Sonnen JA, Koepsell TD, Kukull WA, Larson EB, and Montine TJ (2009) Associations between microinfarcts and other macroscopic vascular findings on neuropathologic examination in 2 databases. Alzheimer Dis Assoc Disord 23: 291-294.

Lourenco MV, Frozza RL, de Freitas GB, Zhang H, Kincheski GC, Ribeiro FC, Gonçalves RA, Clarke JR, Beckman D, Staniszewski A, et al. (2019) Exerciselinked FNDC5/irisin rescues synaptic plasticity and memory defects in Alzheimer's models. Nat Med 25:165-175.

Maezawa I, Nivison M, Montine KS, Maeda N, and Montine TJ (2006a) Neurotoxicity from innate immune response is greatest with targeted replacement of E4 allele of apolipoprotein E gene and is mediated by microglial p38MAPK. FASEB $J \mathbf{2 0}$ : 797-799.

Maezawa I, Zaja-Milatovic S, Milatovic D, Stephen C, Sokal I, Maeda N, Montine TJ, and Montine KS (2006b) Apolipoprotein E isoform-dependent dendritic recovery of hippocampal neurons following activation of innate immunity. $J$ Neuroinflammation $3: 21$.

Mahley RW (2016) Apolipoprotein E: from cardiovascular disease to neurodegenerative disorders. J Mol Med (Berl) 94:739-746.

Martland HS (1928) Punch drunk. JAMA 91:1103-1107.

Mata IF, Samii A, Schneer SH, Roberts JW, Griffith A, Leis BC, Schellenberg GD Sidransky E, Bird TD, Leverenz JB, et al. (2008) Glucocerebrosidase gene mutations: a risk factor for Lewy body disorders. Arch Neurol 65:379-382.

McKee AC, Cairns NJ, Dickson DW, Folkerth RD, Keene CD, Litvan I, Perl DP, Stein TD, Vonsattel JP, Stewart W, et al.; TBI/CTE group (2016) The first NINDS/NIBIB consensus meeting to define neuropathological criteria for the diagnosis of chronic traumatic encephalopathy. Acta Neuropathol 131:75-86.

McKeith IG, Boeve BF, Dickson DW, Halliday G, Taylor JP, Weintraub D, Aarsland D, Galvin J, Attems J, Ballard CG, et al. (2017) Diagnosis and management of dementia with Lewy bodies: fourth consensus report of the DLB Consortium. Neurology 89:88-100

McKhann GM, Knopman DS, Chertkow H, Hyman BT, Jack CR Jr, Kawas CH, Klunk WE, Koroshetz WJ, Manly JJ, Mayeux R, et al. (2011) The diagnosis of dementia due to Alzheimer's disease: recommendations from the National Institute on Aging-Alzheimer's Association workgroups on diagnostic guidelines for Alzheimer's disease. Alzheimers Dement 7:263-269.

Mills SM, Mallmann J, Santacruz AM, Fuqua A, Carril M, Aisen PS, Althage MC Belyew S, Benzinger TL, Brooks WS, et al. (2013) Preclinical trials in autosomal dominant AD: implementation of the DIAN-TU trial. Rev Neurol (Paris) 169: 737-743.

Molinuevo JL, Ayton S, Batrla R, Bednar MM, Bittner T, Cummings J, Fagan AM, Hampel H, Mielke MM, Mikulskis A, et al. (2018) Current state of Alzheimer's fluid biomarkers. Acta Neuropathol 136:821-853.

Montine T and Hulette C (1996) Pathology of ischemic cerebrovascular disease. Neurosurgery. (Wilkins R and Rengachary S eds), vol 2, pp 2045-2051, McGrawHill.

Montine TJ, Phelps CH, Beach TG, Bigio EH, Cairns NJ, Dickson DW, Duyckaerts C, Frosch MP, Masliah E, Mirra SS, et al.; National Institute on Aging; Alzheimer's
Association (2012) National Institute on Aging-Alzheimer's Association guidelines for the neuropathologic assessment of Alzheimer's disease: a practical approach. Acta Neuropathol 123:1-11.

Musiek ES, Xiong DD, and Holtzman DM (2015) Sleep, circadian rhythms, and the pathogenesis of Alzheimer disease. Exp Mol Med 47:e148.

Nelson PT, Dickson DW, Trojanowski JQ, Jack CR, Boyle PA, Arfanakis K, Rademakers R, Alafuzoff I, Attems J, Brayne C, et al. (2019) Limbic-predominant agerelated TDP-43 encephalopathy (LATE): consensus working group report. Brain 142:1503-1527.

Neumann M, Sampathu DM, Kwong LK, Truax AC, Micsenyi MC, Chou TT, Bruce J, Schuck T, Grossman M, Clark CM, et al. (2006) Ubiquitinated TDP-43 in frontotemporal lobar degeneration and amyotrophic lateral sclerosis. Science 314: 130-133.

Ou SH, Wu F, Harrich D, García-Martínez LF, and Gaynor RB (1995) Cloning and characterization of a novel cellular protein, TDP-43, that binds to human immunodeficiency virus type 1 TAR DNA sequence motifs. $J$ Virol 69:3584-3596.

Postupna N, Keene CD, Crane PK, Gonzalez-Cuyar LF, Sonnen JA, Hewitt J, Rice S, Howard K, Montine KS, Larson EB, et al. (2015) Cerebral cortical A $\beta 42$ and PHF- $\tau$ in 325 consecutive brain autopsies stratified by diagnosis, location, and APOE. $J$ Neuropathol Exp Neurol 74:100-109.

Reiman EM, Arboleda-Velasquez JF, Quiroz YT, Huentelman MJ, Beach TG, Caselli RJ, Chen Y, Su Y, Myers AJ, Hardy J, et al.; Alzheimer's Disease Genetics Consortium (2020) Exceptionally low likelihood of Alzheimer's dementia in APOE2 homozygotes from a 5,000-person neuropathological study. Nat Commun 11:667.

Riedl L, Mackenzie IR, Förstl H, Kurz A, and Diehl-Schmid J (2014) Frontotemporal lobar degeneration: current perspectives. Neuropsychiatr Dis Treat 10:297-310.

Ross R (1986) The pathogenesis of atherosclerosis--an update. $N$ Engl J Med 314: 488-500.

Rothman SM and Mattson MP (2013) Activity-dependent, stress-responsive BDNF signaling and the quest for optimal brain health and resilience throughout the lifespan. Neuroscience 239:228-240.

Schellenberg GD and Montine TJ (2012) The genetics and neuropathology of Alzheimer's disease. Acta Neuropathol 124:305-323.

Schneider SA and Alcalay RN (2020) Precision medicine in Parkinson's disease: emerging treatments for genetic Parkinson's disease. J Neurol 267:860-869.

Shah NS, Vidal JS, Masaki K, Petrovitch H, Ross GW, Tilley C, DeMattos RB, Tracy RP, White LR, and Launer LJ (2012) Midlife blood pressure, plasma $\beta$-amyloid, and the risk for Alzheimer disease: the Honolulu Asia Aging Study. Hypertension 59:780-786.

Sidransky E, Nalls MA, Aasly JO, Aharon-Peretz J, Annesi G, Barbosa ER, Bar-Shira A, Berg D, Bras J, Brice A, et al. (2009) Multicenter analysis of glucocerebrosidase mutations in Parkinson's disease. N Engl J Med 361:1651-1661.

Sieber BA, Landis S, Koroshetz W, Bateman R, Siderowf A, Galpern WR, Dunlop J, Finkbeiner S, Sutherland M, Wang H, et al.; Parkinson's Disease 2014: Advancing Research, Improving Lives Conference Organizing Committee (2014) Prioritized research recommendations from the national Institute of neurological disorders and stroke Parkinson's disease 2014 conference. Ann Neurol 76: $469-472$

Singleton AB, Hardy JA, and Gasser T (2017) The birth of the modern era of Parkinson's disease genetics. J Parkinsons Dis 7 (Suppl 1):S87-S93.

Sonnen JA, Breitner JC, Lovell MA, Markesbery WR, Quinn JF, and Montine TJ (2008) Free radical-mediated damage to brain in Alzheimer's disease and its transgenic mouse models. Free Radic Biol Med 45:219-230.

Sonnen JA, Larson EB, Brickell K, Crane PK, Woltjer R, Montine TJ, and Craft S (2009) Different patterns of cerebral injury in dementia with or without diabetes. Arch Neurol 66:315-322.

Sonnen JA, Larson EB, Crane PK, Haneuse S, Li G, Schellenberg GD, Craft S, Leverenz JB, and Montine TJ (2007) Pathological correlates of dementia in a longitudinal, population-based sample of aging. Ann Neurol 62:406-413.

Sperling RA, Aisen PS, Beckett LA, Bennett DA, Craft S, Fagan AM, Iwatsubo T, Jack CR Jr, Kaye J, Montine TJ, et al. (2011) Toward defining the preclinical stages of Alzheimer's disease: recommendations from the National Institute on Aging-Alzheimer's Association workgroups on diagnostic guidelines for Alzheimer's disease. Alzheimers Dement 7:280-292.

Stewart W, Allinson K, Al-Sarraj S, Bachmeier C, Barlow K, Belli A, Burns MP, Carson A, Crawford F, Dams-O'Connor K, et al. (2019) Primum non nocere: a call for balance when reporting on CTE [published correction appears in Lancet Neurol (2019) 18:e3]. Lancet Neurol 18:231-233.

Terry RD and Katzman R (2001) Life span and synapses: will there be a primary senile dementia? Neurobiol Aging 22:347-348; discussion 353-354.

Tolar M, Abushakra S, Hey JA, Porsteinsson A, and Sabbagh M (2020) Aducanumab, gantenerumab, BAN2401, and ALZ-801-the first wave of amyloid-targeting drugs for Alzheimer's disease with potential for near term approval. Alzheimers Res Ther 12:95.

Tsuang D, Leverenz JB, Lopez OL, Hamilton RL, Bennett DA, Schneider JA, Buchman AS, Larson EB, Crane PK, Kaye JA, et al. (2013) APOE $\varepsilon 4$ increases risk for dementia in pure synucleinopathies. JAMA Neurol 70:223-228.

Veitch DP, Weiner MW, Aisen PS, Beckett LA, Cairns N.J, Green RC, Harvey D, Jack CR Jr, Jagust W, Morris JC, et al. Alzheimer's Disease Neuroimaging Initiative (2019) Understanding disease progression and improving Alzheimer's disease clinical trials: recent highlights from the Alzheimer's Disease Neuroimaging Initiative. Alzheimers Dement 15:106-152.

Wang LY, Larson EB, Sonnen JA, Shofer JB, McCormick W, Bowen JD, Montine TJ, and Li G (2009) Blood pressure and brain injury in older adults: findings from a community-based autopsy study. J Am Geriatr Soc 57:1975-1981.

Weiner MW, Crane PK, Montine TJ, Bennett DA, and Veitch DP (2017) Traumatic brain injury may not increase the risk of Alzheimer disease. Neurology $\mathbf{8 9}$ $1923-1925$

White LR, Edland SD, Hemmy LS, Montine KS, Zarow C, Sonnen JA, Uyehara-Lock JH, Gelber RP, Ross GW, Petrovitch H, et al. (2016) Neuropathologic comorbidity 
and cognitive impairment in the nun and Honolulu-Asia aging studies. Neurology 86:1000-1008.

Williamson JD, Pajewski NM, Auchus AP, Bryan RN, Chelune G, Cheung AK Cleveland ML, Coker LH, Crowe MG, Cushman WC, et al.; SPRINT MIND Investigators for the SPRINT Research Group (2019) Effect of intensive vs standard blood pressure control on probable dementia: a randomized clinical trial JAMA 321:553-561.
Zhao L, Gottesdiener AJ, Parmar M, Li M, Kaminsky SM, Chiuchiolo MJ, Sondhi D, Sullivan PM, Holtzman DM, Crystal RG, et al. (2016) Intracerebral adenoassociated virus gene delivery of apolipoprotein E2 markedly reduces brain amyloid pathology in Alzheimer's disease mouse models. Neurobiol Aging 44:159-172. Zhao N, Attrebi ON, Ren Y, Qiao W, Sonustun B, Martens YA, Meneses AD, Li F, Shue F, Zheng J, et al. (2020) APOE4 exacerbates $\alpha$-synuclein pathology and related toxicity independent of amyloid. Sci Transl Med 12:eaay1809. 